Nat. Hazards Earth Syst. Sci., 17, 1779-1793, 2017

https://doi.org/10.5194/nhess-17-1779-2017

(C) Author(s) 2017. This work is distributed under

the Creative Commons Attribution 4.0 License.

\title{
GB-InSAR monitoring of slope deformations in a mountainous area affected by debris flow events
}

\author{
William Frodella, Teresa Salvatici, Veronica Pazzi, Stefano Morelli, and Riccardo Fanti \\ Department of Earth Sciences, University of Firenze, Via La Pira 4, 50121 Florence, Italy \\ Correspondence to: William Frodella (william.frodella@unifi.it)
}

Received: 8 June 2017 - Discussion started: 20 June 2017

Revised: 23 August 2017 - Accepted: 1 September 2017 - Published: 19 October 2017

\begin{abstract}
Diffuse and severe slope instabilities affected the whole Veneto region (north-eastern Italy) between 31 October and 2 November 2010, following a period of heavy and persistent rainfall. In this context, on 4 November 2010 a large detrital mass detached from the cover of the Mt. Rotolon deep-seated gravitational slope deformation (DSGSD), located in the upper Agno River valley, channelizing within the Rotolon Creek riverbed and evolving into a highly mobile debris flow. The latter phenomena damaged many hydraulic works, also threatening bridges, local roads, and the residents of the Maltaure, Turcati, and Parlati villages located along the creek banks and the town of Recoaro Terme. From the beginning of the emergency phase, the civil protection system was activated, involving the National Civil Protection Department, Veneto Region, and local administrations' personnel and technicians, as well as scientific institutions. On 8 December 2010 a local-scale monitoring system, based on a ground-based interferometric synthetic aperture radar (GBInSAR), was implemented in order to evaluate the slope deformation pattern evolution in correspondence of the debris flow detachment sector, with the final aim of assessing the landslide residual risk and managing the emergency phase. This paper describes the results of a 2-year GB-InSAR monitoring campaign (December 2010-December 2012) and its application for monitoring, mapping, and emergency management activities in order to provide a rapid and easy communication of the results to the involved technicians and civil protection personnel, for a better understanding of the landslide phenomena and the decision-making process in a critical landslide scenario.
\end{abstract}

\section{Introduction}

Deep-seated gravitational slope deformations (DSGSDs) are normally not considered hazardous phenomena due to their typically very slow evolution; nevertheless, under certain conditions ground movements can accelerate evolving into faster mass movements, which may favour collateral landslide processes (Crosta, 1996; Crosta and Agliardi, 2003). Therefore, a multidisciplinary approach is fundamental in order to understand the complex nature of such phenomena so as to assess the correct mitigation measures. In this framework advanced mapping methods, based on spaceborne, aerial, and terrestrial remote sensing platforms, represent the optimal solution for landslide detection, monitoring, and mapping in various physiographic and land cover conditions, particularly with large phenomena and hazardous nonaccessible sectors (Casagli, 2017b; Guzzetti et al., 2012). In recent decades, many advanced remote sensing technologies have gained widespread recognition as efficient remote surveying techniques for the characterization and monitoring of landslide-affected areas in terms of resolution, accuracy, data visualization, management, and reproducibility. Among these are digital photogrammetry (Chandler, 1999; Zhang et al., 2004), laser scanning (Abellan et al., 2006; Gigli et al., 2012, 2014c; Jaboyedoff et al., 2012; Tapete et al., 2012), infrared thermography (Gigli et al., 2014a, b; Frodella et al., 2015), and radar interferometry, both terrestrial and satellite (Luzi et al., 2004; Casu et al., 2006; Bardi et al., 2014; Tofani et al., 2014; Ciampalini et al., 2016; Gullà et al., 2017; Nicodemo et al., 2016; Peduto et al., 2017a, b).

Ground-based interferometric synthetic aperture radar (GB-InSAR) systems in particular, for their ability to measure displacements with high geometric accuracy, temporal sampling frequency, and adaptability to specific applications 


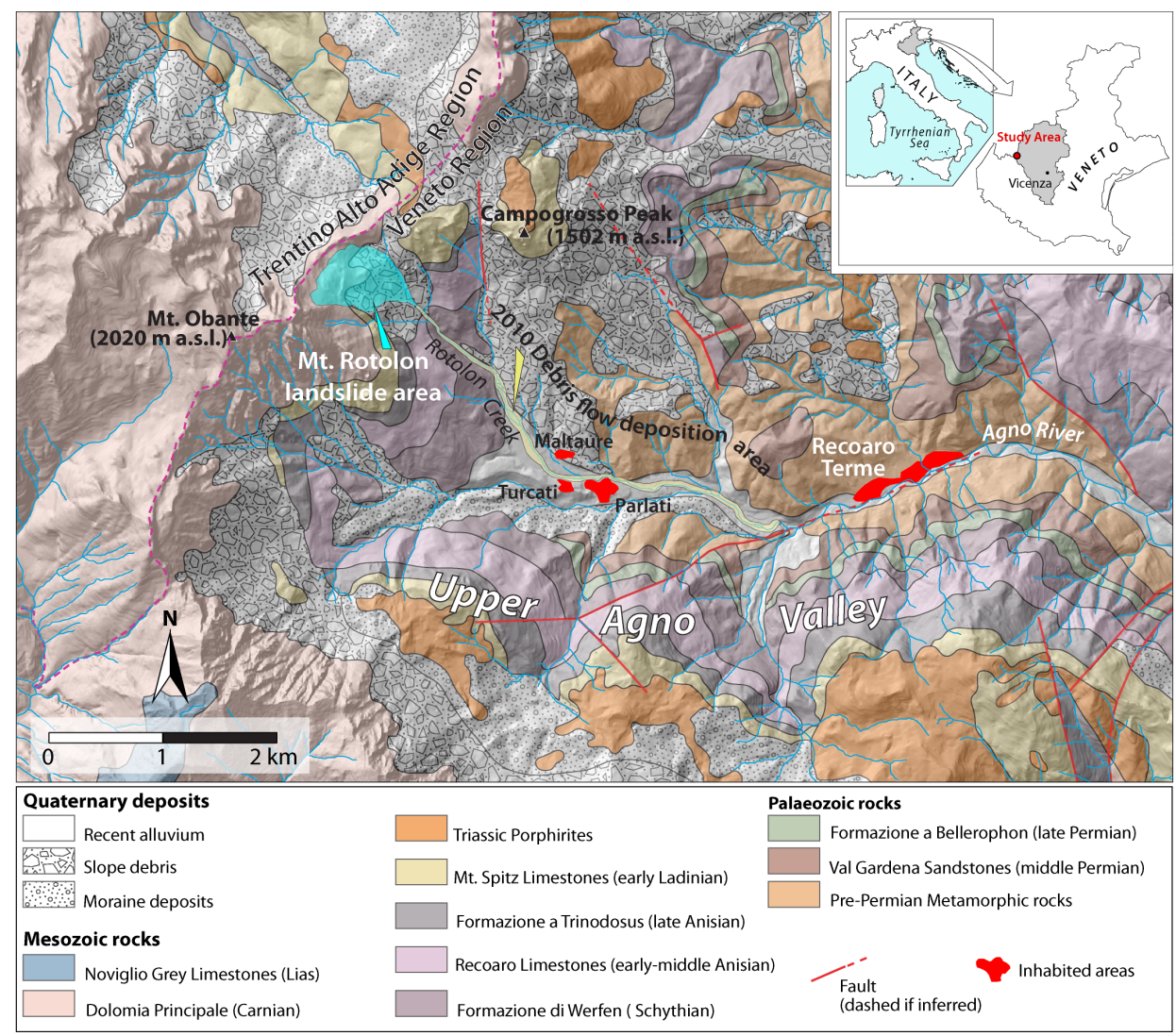

Figure 1. Geological sketch map of the upper Agno River valley with the location of the Rotolon landslide.

(Monserrat et al., 2014), represent powerful devices successfully employed in (a) engineering and geological applications for detecting structural deformation and surface ground displacements (Tarchi et al., 1997, 2003; Antonello et al., 2004; Casagli et al., 2010, 2017a), (b) monitoring of volcanic activity (Nolesini et al., 2013; Di Traglia et al., 2014a), and (c) stability analysis of historical towns built on isolated hilltops (Luzi et al., 2004; Frodella et al., 2016; Nolesini et al., 2016). Furthermore, in recent years the GB-InSAR technique has developed to an extent where it can significantly contribute to the management of major technical and environmental disasters (Del Ventisette et al., 2011; Broussolle et al., 2014; Lombardi et al., 2017; Bardi et al., 2017a, b). Between 31 October 2010 and 2 November 2010 the whole Veneto region (north-eastern Italy; Fig. 1) was hit by heavy and persistent rainfall, that triggered widespread flooding and abundant slope failures, causing extensive damage to people (3 fatalities and about 3500 evacuated people) and structures, in addition to heavy economic losses in agricultural, livestock, and industrial activities.

In this context, on 4 November 2010, part of detrital cover of the Rotolon DSGSD suffered the detachment of a mass approximately $320000 \mathrm{~m}^{3}$ in volume, which channelized in the Rotolon Creek bed and caused a large debris flow. This phenomenon was characterized by more than $3 \mathrm{~km}$ of run- out, damaging various hydraulic works (creek dams, weirs, bank protections) and threatening various structures (bridges, local roads, houses) as well as those residing in the villages of Maltaure, Turcati, and Parlati and the town of Recoaro Terme; Fig. 1).

On 8 December 2010 a GB-InSAR monitoring system was implemented in order to assess the landslide residual displacements and support the local authorities in the emergency management (Fidolini et al., 2015), calling into play both the national (DPC) and regional (DPCR) civil protection departments, in cooperation with scientific institutions (namely "competence centres"), local administration personnel, and technicians (Bertolaso et al., 2009; Pagliara et al., 2014; Ciampalini et al., 2015). Accurate geomorphological field surveys were also carried out in this phase in order to analyse the landslide morphological features and improve the radar data interpretation (Frodella et al., 2014, 2015, 2017). In addition, a 3-D landslide run-out numerical model was performed to identify the source and impact areas of potential debris flow events, flow velocity, and deposit distribution within the Rotolon Creek valley (Salvatici et al., 2017).

This work is focused on the results of a long-term continuous GB-InSAR monitoring campaign (December 2010December 2012) carried out during the post-event recovery phase, in which monitoring, mapping, and emergency man- 


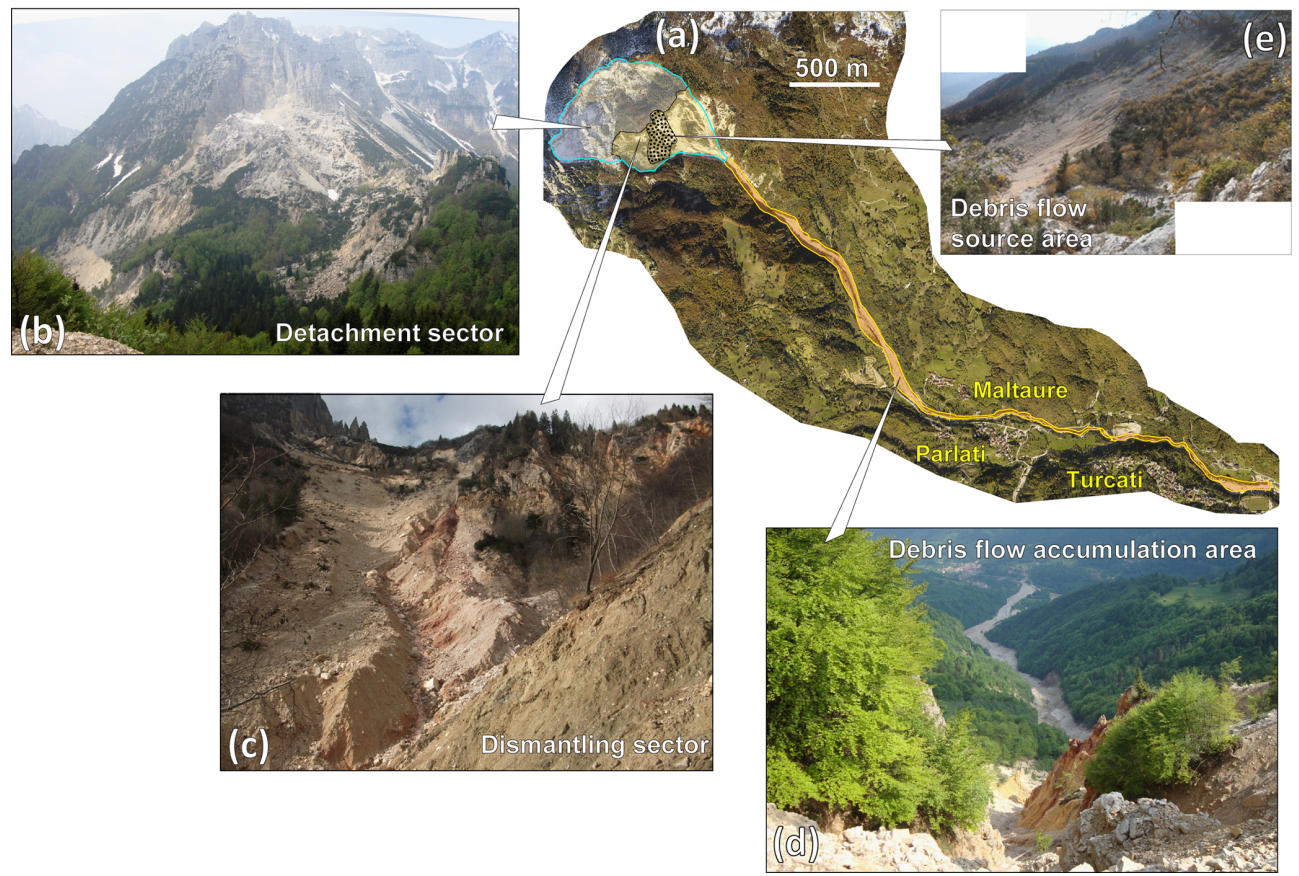

Figure 2. The Mt. Rotolon DSGSD plan (a): landslide sectors (b, c) and the 2010 debris flow features (d, e).

agement activities were implemented to assess the landslide residual risk and analyse its kinematics. In this context field activities were carried out by local civil protection operators and technicians for a validation of the remotely sensed data (landslide area inspections). In particular, the analysed radar data were shared with the technicians and civil protection personnel involved in order to provide a rapid and easy communication of the results and to enhance the synergy of all the subjects involved in the recovery phase.

\section{Study area}

The Rotolon DSGSD is located in the Vicentine Prealps, on the south-eastern flank of the Little Dolomites chain, in the uppermost Agno river valley (Fig. 1). The instable processes of the area, such as slope failures and debris flows induced as secondary phenomena of the DSGSD, have threatened the upper Agno valley for centuries (Frodella et al., 2014). From a geological point of view, the landslide develops in the uppermost portion of a mainly dolomitic-limestone stratigraphic succession, sub-horizontally bedded from middle Triassic to lower Jurassic in age, belonging to the South Alpine domain (De Zanche and Mietto, 1981).

The mass movement is delimited to the NW by the ridge of the Mt. Obante group and develops from about 1700 to $1100 \mathrm{~m}$ a.s.l., covering an area of $448000 \mathrm{~m}^{2}$. The Rotolon DSGSD can be classified as a DSGSD ("sackung type"; Zischinsky, 1969) and characterized by complex activity (Cruden and Varnes, 1996) causing a rough morphology with steep scarps, trenches, crests, and counterscarps (Figs. 2 and 3).

Two distinct sectors can be identified, based on the dominant slope instability processes in act: (i) an upper "detachment sector", followed downstream by a (ii) "dismantling sector" (Frodella et al., 2014). The detachment sector (with a mean slope of $30^{\circ}$ ) develops downstream from the main landslide crown (Figs. 2a, b and 3) and is dominated by extensional deformation causing the development of tensional fractures, resulting in alternate trenches and crests creating a very rough, stepped topographic surface. This area is affected by gravitational and erosional processes, as well as the rock mass detensioning and disaggregation, resulting in the accumulation of various depositional elements (colluvial fans, colluvial aprons, rockfall and rock avalanche deposits) formed by very coarse heterometric clasts, ranging from cobbles to boulders with scattered blocks (decimetric to decametric in size) in a coarse sandy matrix (Figs. 3 and 4).

The dismantling area (mean slope of $34^{\circ}$ ) includes sectors formed by highly weathered sub-vertical rock walls. It is dominated by surface processes (e.g. concentrated and diffuse erosion, slope-waste deposition due to gravity, detrital cover failures) that substantially cover the evidence of deeper deformations (Figs. 3 and 4). This area supplies material for debris flows, which channelize downstream within the Rotolon Creek bed, representing the most critical sector for short-term hazardous phenomena. 


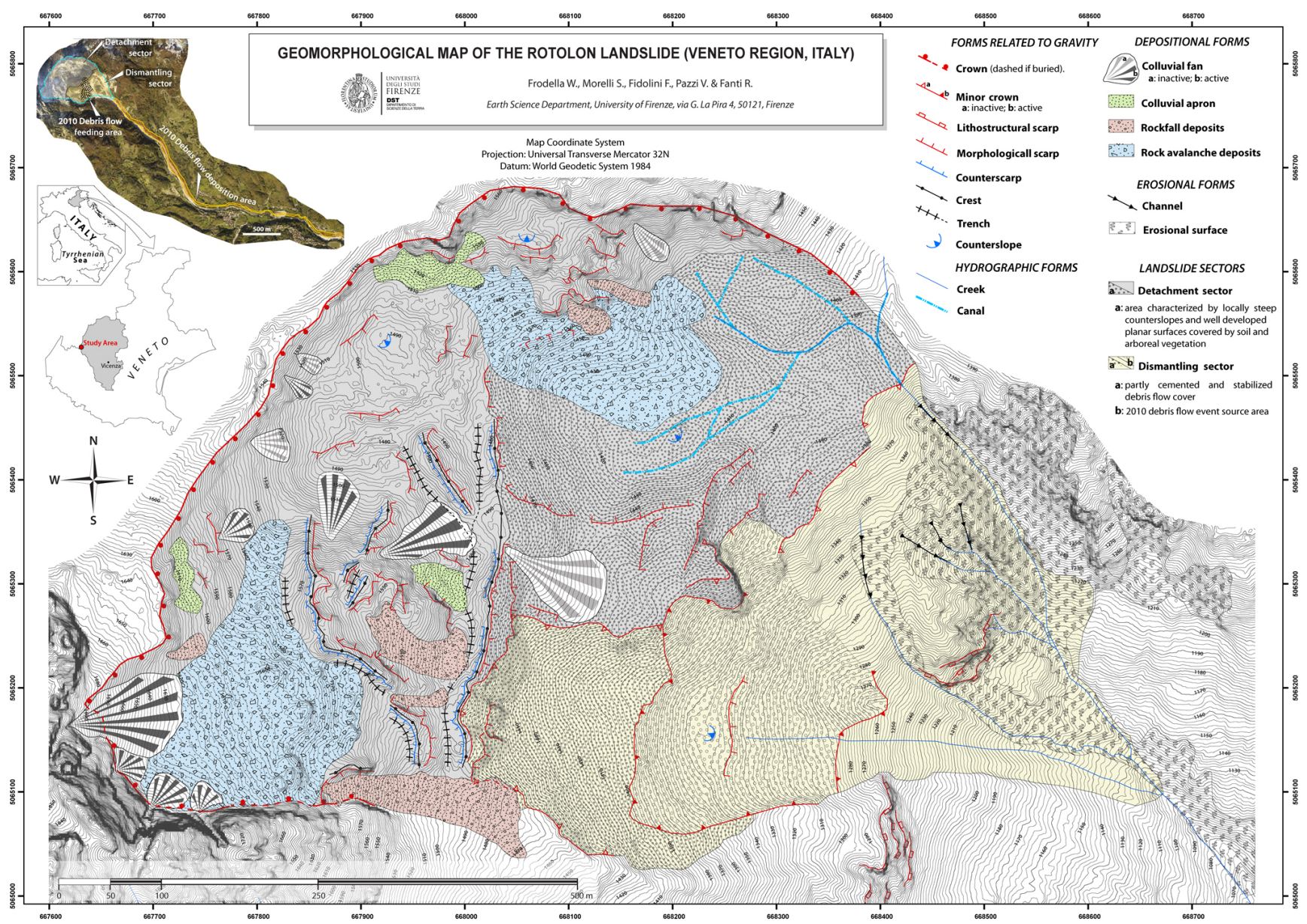

Figure 3. Geomorphological map of the Rotolon Landslide (modified after Frodella et al., 2014).
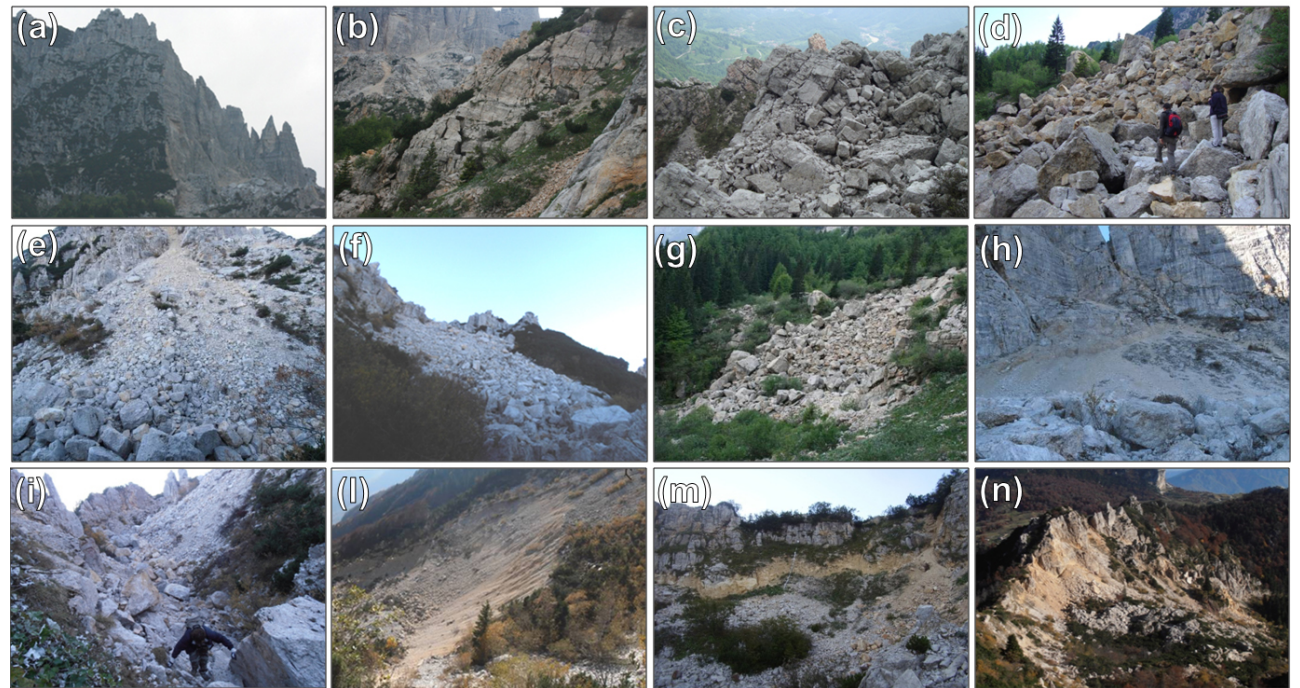

Figure 4. Geomorphic and sedimentary features of the Mt. Rotolon DSGSD detachment sector: (a) rock walls prone to rockfalls; (b, c) rock mass affected by different stages of disaggregation; (d) plurimetric rock blocks within rock avalanche deposit. Main depositional elements within the landslide body: (e) colluvial fan; (f, g) channelized and diffused rockfall deposits; (h) colluvial aprons. Main landslide linear elements: (i) landslide trench; (l) 2010 debris flow detachment scarp; (m) DSGSD crown sector; (n) landslide crest. 

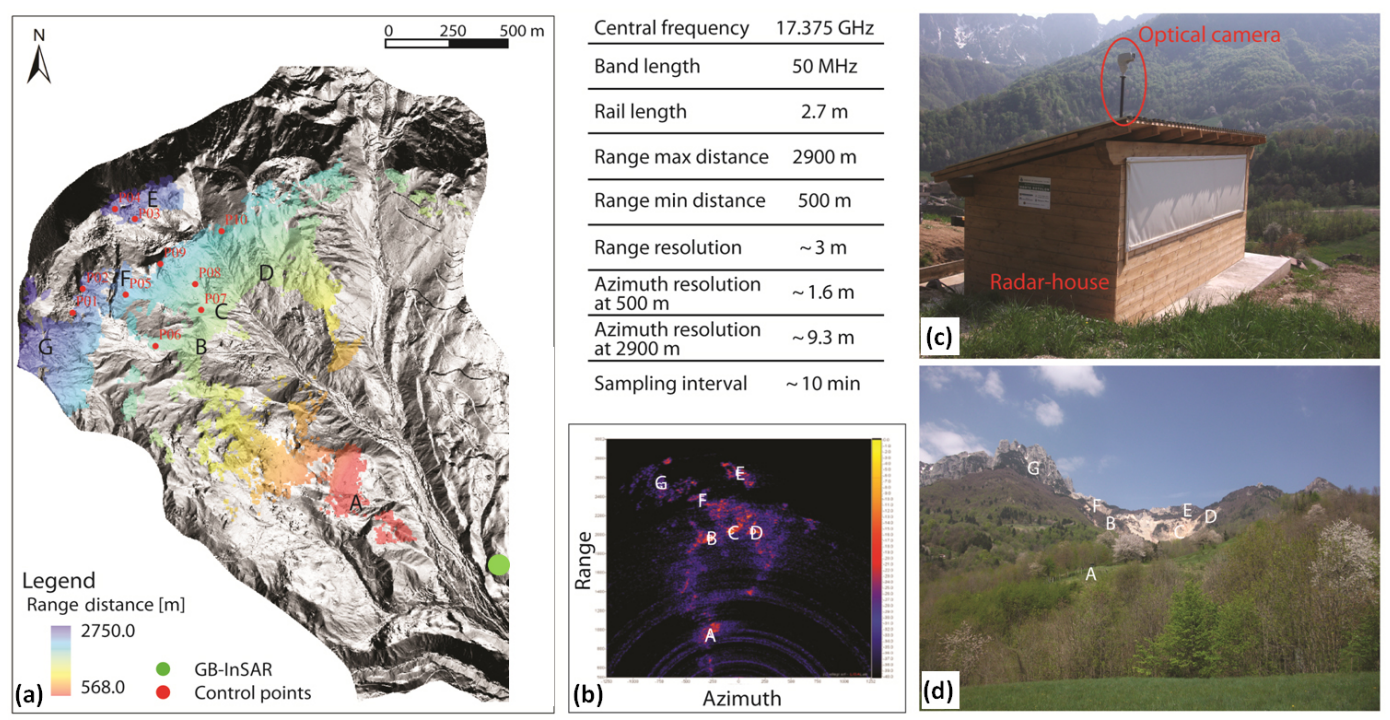

Figure 5. The adopted monitoring system: (a) location of the GB-InSAR system and radar data coverage features (A-G are recognized landslide sectors); (b) the adopted monitoring parameters and radar power image, displaying the correspondent recognized landslide sectors; (c) the radar system hut setting; (d) picture of the monitoring optical system scenario (A-G are corresponding sectors).

\section{The GB-InSAR technique: basic theoretical principles}

The GB-InSAR is a computer-controlled microwave transmitting and receiving antenna that moves along a mechanical linear rail in order to synthesize a linear aperture along the azimuth direction (Tarchi et al., 1997). The device radiates microwaves in the $\mathrm{Ku}$ band $(12-18 \mathrm{GHz})$ and registers the backscattered signal in the acquiring time interval (less than 1 min with the most modern systems). Each acquisition produces a complex matrix of values from which phase and amplitude information is calculated (Luzi et al., 2004; Luzi, 2010). A SAR image contains amplitude and phase information of the observed objects' backscattered echo within the investigated scenario, and it is obtained by combining the spatial resolution along the direction perpendicular to the rail (range resolution, $\Delta R_{\mathrm{r}}$ ) and the one parallel to the synthetic aperture (azimuth or cross-range resolution, $\Delta R_{\mathrm{az}}$ ) (Luzi, 2010). The working principle of the GB-InSAR technique is the evaluation of the phase difference, pixel by pixel, between two pairs of averaged sequential SAR complex images, which forms an interferogram (Bamler and Hartl, 1998). The latter does not contain topographic information, given the antennas fixed position during different scans (zero baseline condition). Therefore, in the elapsed time between the acquisitions of two or more subsequent coherent SAR images, it is possible to derive from the obtained interferograms a 2-D map of the displacements that occurred along the sensor LOS (line of sight; Tarchi et al., 1997, 2003; Pieraccini et al., 2000, 2002). The capability of InSAR to detect ground displacement depends on the persistence of phase coherence (ranging from 0 to 1 ) over appropriate time intervals (Luzi,
2010). Among the technique's advantages it must be noted that GB-InSAR works (a) without any physical contact with the slope, avoiding the need of accessing the area; (b) in almost any light and atmospheric condition; (c) continuously over a long time; (d) with millimetric accuracy (the accuracy of the measured phase is usually a fraction of the operated wavelength; Luzi, 2010); (e) by providing extensive and detailed near-real-time information of the whole visible slope.

This last feature in particular provides a strong advantage to the traditional ground surface methods (like inclinometers, extensometers, total stations), which provide single-point information in accessible areas and are generally not sufficient to evaluate the kinematics and potential behaviour of a complex landslide. The main drawback of the technique is the logistics of the installation platform, both because the GBInSAR system measures only the displacement component parallel to LOS and because the azimuth resolution (the ability to separate two objects perpendicular to the distance between the sensor and the target) lessens with the increase of the distance from the target (Fig. 5). Moreover, vegetated areas can be another drawback of the technique since they are commonly characterized by low signal coherence and power intensity.

\section{The GB-InSAR monitoring strategy in the Rotolon early warning system}

The GB-InSAR system was installed in the village of Maltaure, at an average distance of $3 \mathrm{~km}$ from the landslide, pointing upwards to NW (Fig. 5). The radar parameters are summarized in Fig. 5. Given the acquisition setting of the site 


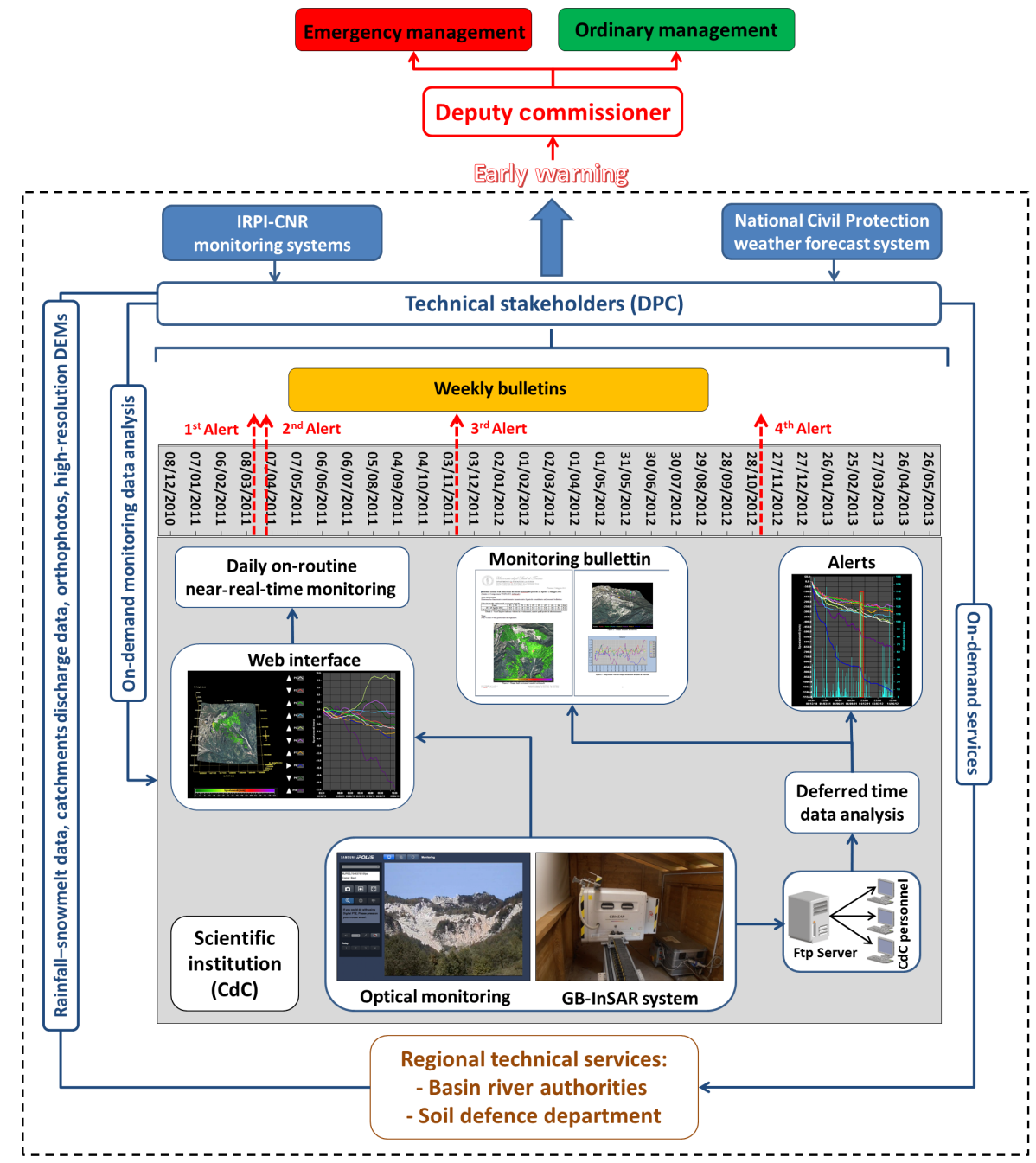

Figure 6. Timeline rationale of the Rotolon monitoring system and emergency management procedures. The black dashed box includes the early warning system.

and the civil protection needs, the radar data cover an area of $1.2 \mathrm{~km}^{2}$. The logistics of the GB-InSAR system installation favoured a good spatial coverage of the data on the monitored area, especially with regards to the dismantling sector. Nevertheless, shadowing effects, due to the slope roughness, crests, and counter-slope surfaces, affect the detachment sectors (Figs. 5 and 7).

The radar system acquired GB-InSAR data every $10 \mathrm{~min}$, from which cumulated 2-D displacement maps and displacement time series of 10 measuring points (Fig. 5) were obtained. GB-InSAR data were processed using LiSALab software (Ellegi s.r.l.) and uploaded via LAN network: (i) on a dedicated web-based interface, allowing for a near-realtime data on-routine visualization and (ii) on a remote ftp server (in ASCII format), in order to perform on demand analysis in case of critical weather events forecast by the national civil protection weather system (Fig. 6). The latter were performed integrating into a GIS environment the displacement maps and comparing them with ancillary data (rainfall, geological and geomorphological maps). In addition, a remotely adjustable robotized high-resolution optical camera (Ulisse Compact model produced by Videotec S.p.A, digital zoom $10 \times-36 \times$ ), manoeuvrable via IP-Ethernet interface, was installed in correspondence with the radar system, acquiring data every $60 \mathrm{~min}$ and allowing for programmable zooms. The objective of this device was to check the hazardous and inaccessible dismantling sector of the landslide (Figs. 5 and 6).

Based on these displacements acquisition modes, a localscale early warning system (Intrieri et al., 2012, 2013) was implemented considering three different levels of attention: ordinary, pre-alarm, and alarm levels (Fig. 5). In order to support the civil protection decision-making, hourly displacement thresholds were adopted. The level change occurred when the following thresholds were surpassed: (i) ordinary at $<0.1 \mathrm{mmh}^{-1}$; (ii) pre-alarm at $0.1-0.5 \mathrm{mmh}^{-1}$; 
and (iii) alarm level at $>0.5 \mathrm{mmh}^{-1}$. For each threshold different actions were planned: (i) regular monitoring but no additional actions; (ii) on demand monitoring data and analysis and $4 \mathrm{~h}$ bulletins; (iii) integration with other external monitoring data and activation request of the alert system once false warnings are prevented. This last point was achievable thanks to the ability of the radar output data to be integrated and promptly analysed in a commensurable manner with records from different devices. In this specific case they were represented by traditional instruments (one total station with a benchmarks network, one rain gauge, and six extensometers; Frigerio et al., 2014) operated by the Research Institute for Geo-Hydrological Protection of the Italian National Research Council (IRPI-CNR). To define these stability thresholds, since there was no a previous knowledge of the phenomenon behaviour, a deeper inspection of cumulated images (incremental method) and interferograms (rolling method) were carried out in the first month of activity in seven sectors visible from the station and characterized by high reflectivity (mainly rocky and bare terrains), including the landslide area and all the surrounding slopes, which were considered stable (A-G in Fig. 5). This double analysis, useful to overcome possible misinterpretations caused by noise signal, was finally refined in relation to expected dynamics of the investigated instable slope. During the entire monitoring period, communication with the deputy commissioner and cooperators was operated through the dispatch of informative bulletins every week and whenever the warning thresholds were exceeded. The timeline rationale of the monitoring system and emergency management procedures is summarized in Fig. 6.

\section{GB-InSAR data analysis}

The GB-InSAR incremental cumulative displacement (ICD) maps and the displacement time series of the measuring points obtained are shown in Figs. 7 and 8, respectively. By using a selected colour scale, the radar maps obtained are displayed as a function of the displacement measured in the period spanning from 8 December 2010 to the beginning of each month of the monitoring campaign, (the negative displacement values indicate movements approaching the sensor; Fig. 7). In order to evaluate the deformation rates and provide easily interpretable data, a traffic-light-type colour scale was applied in all the displacement maps.

GB-InSAR measuring points (corresponding to a $5 \times 5$ pixel size area) were selected in correspondence with sectors where the radar signal is characterized by high stability, in order to monitor the landslide kinematics and characterize the various landslide physiographic features (Fig. 7). Furthermore, with the aim of performing a temporally detailed displacement analysis and detecting the spatial pattern of residual landslide deformation, monthly cumulated displacement
(MCD) maps were also selected and analysed from the collected GB-InSAR dataset (Fig. 9).

From the analysis of the collected GB-InSAR dataset of the ICD maps (Fig. 7) four distinct areas characterized by relevant residual cumulated displacement were identified (Fig. 7d):

- Area $1\left(\mathrm{ICD}=737 \mathrm{~mm}\right.$, about $12500 \mathrm{~m}^{2}$ in extension $)$ and Area $2\left(\mathrm{ICD}=751 \mathrm{~mm}\right.$, area of $\left.28000 \mathrm{~m}^{2}\right)$, corresponding to the material infilling the detachment sector (Fig. 2), such as minor rockfall and rock avalanche deposits;

- Area $3\left(\mathrm{ICD}=960 \mathrm{~mm} ; 12000 \mathrm{~m}^{2}\right.$ in extension) and Area $4\left(\mathrm{ICD}=2437 \mathrm{~mm} ; 88000 \mathrm{~m}^{2}\right.$ coverage $)$, both falling within the dismantling sector detrital cover (Fig. 2), which was not affected by the 2010 debris flow detachment.

The measuring points time series (Fig. 8) display cumulated displacements ranging from $337 \mathrm{~mm}$ (Point 6) to $595 \mathrm{~mm}$ (Point 4, located in Area 1); Point 8 in particular (falling within Area 4) displays the monitored area cumulated peak displacements $(\mathrm{ICD}=1476 \mathrm{~mm})$, showing two acceleration periods (middle March 2011 and beginning of November 2011), alternating with a more linear trend. The comparison amongst the MCD maps highlighted a first phase of widespread residual displacements (December 2010; Fig. 9a), which gradually decreased from the following month (Fig. 9b). In the subsequent period ground deformation took place in correspondence with limited sectors within Area 4 (May 2011 in particular shows higher MCD up to $244 \mathrm{~mm}$; Fig. 9d), except for a widespread reactivation recorded in November 2011 (Fig. 9e).

Furthermore, in order to automatically extract the most hazardous residual displacement sectors, the MCD dataset was analysed by means of a MATLAB code (Salvatici et al., 2017) (Fig. 10). The code extracts from the dataset all of the areas affected by deformation higher than a selected threshold value, set equal to $92.3 \mathrm{~mm}$, being the minimum displacement among all the maximum MCD values. The results are displacement maps showing only the areas with such selected displacements (Fig. 10a-d), confirming the trend highlighted by the MCD maps (Fig. 9). The second operation of the employed code consists in the frequency calculation of the displacement occurred (the code computes how many times each pixel has recorded the selected displacement during the monitoring period) (Fig. 10e). By using this method, three critical areas characterized by repeated residual reactivations were detected: Area 2, Area 3 (one reactivation) and especially Area 4 (eight reactivations).

\section{Discussion}

Successful strategies for landslide residual hazard assessment and risk reduction would imply integrated methodolo- 

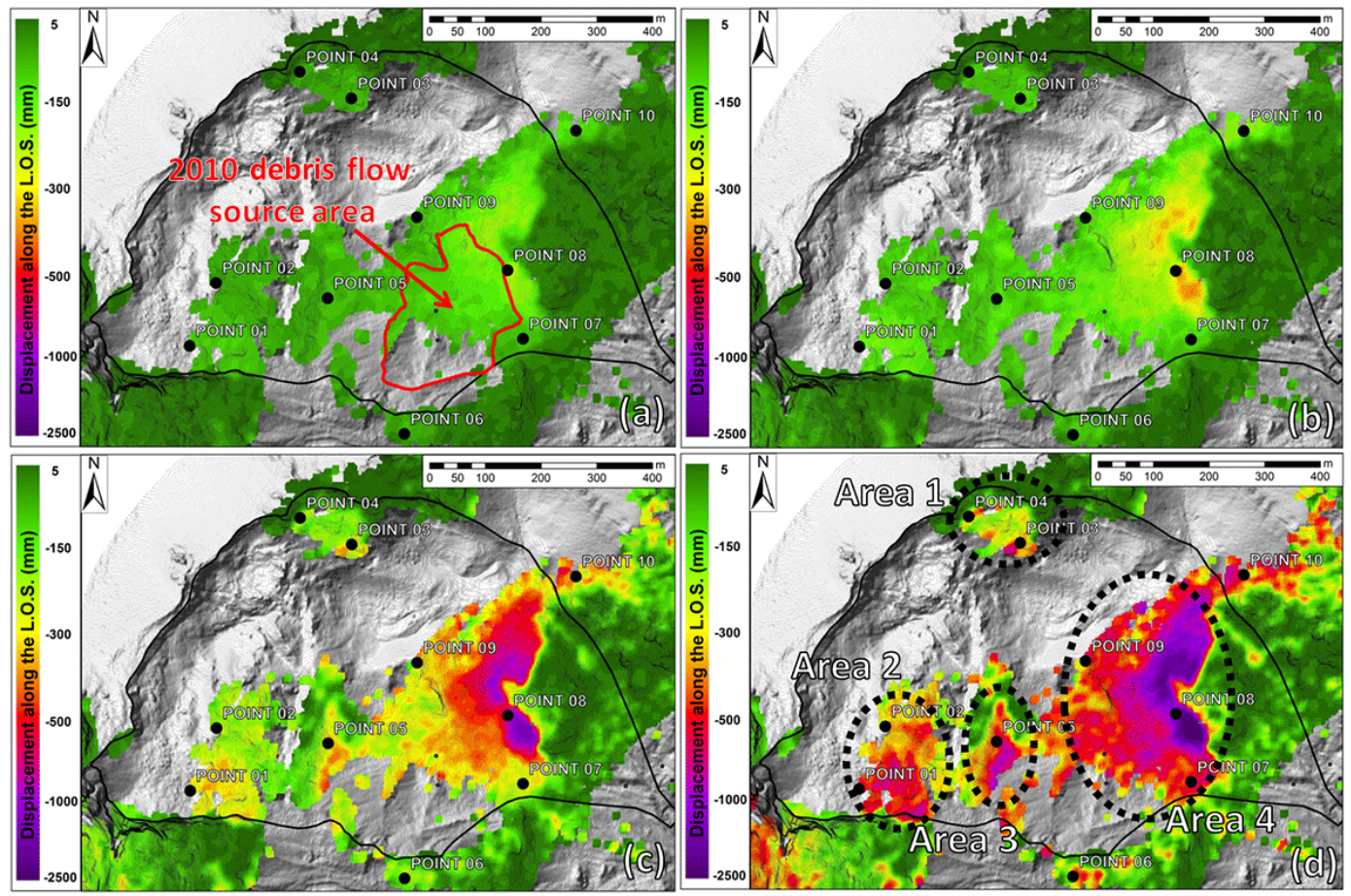

Figure 7. ICD maps of the Rotolon landslide: (a) 8 December 2010-1 January 2011; (b) 8 December 2010-1 February 2011; (c) 8 December 2010-1 December 2011; (d) 8 December 2010-31 December 2012 (points 1-10 represent the GB-InSAR measurement points in correspondence of which the displacement time series were extracted).

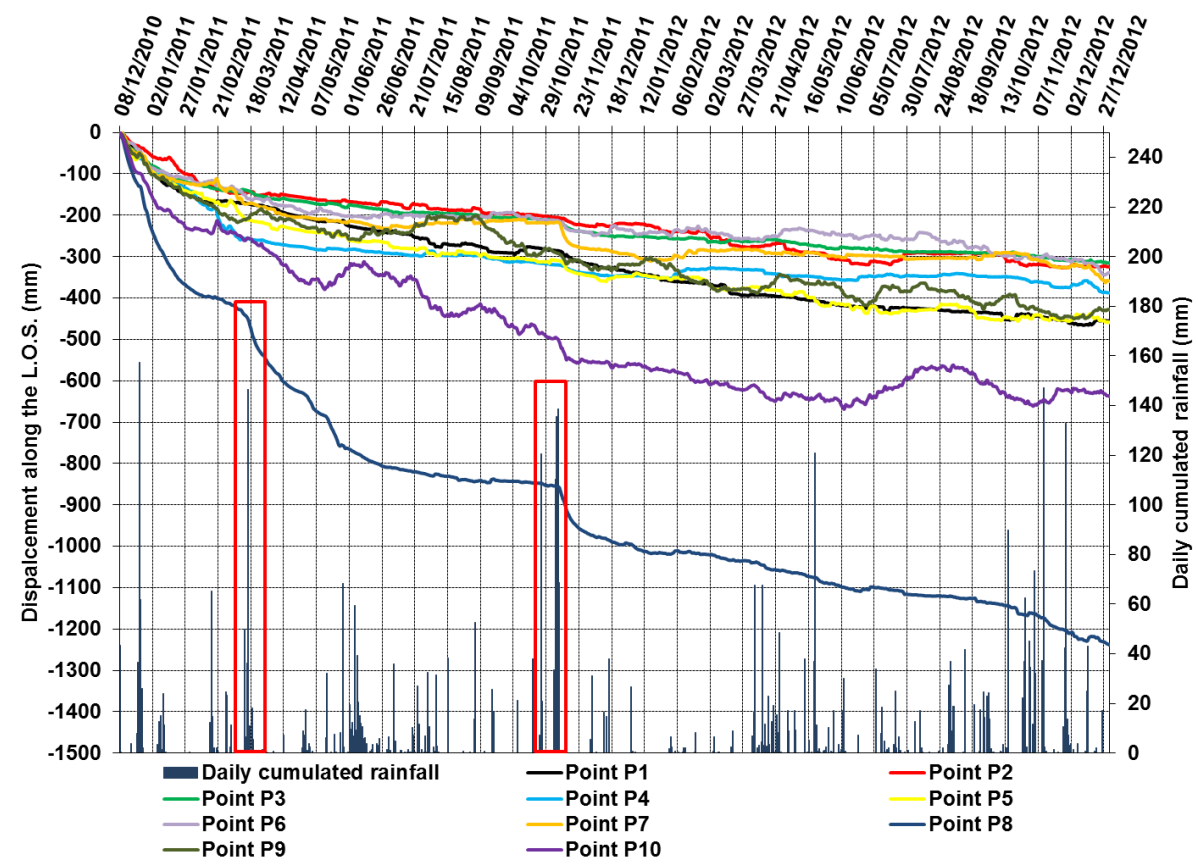

Figure 8. Selected measuring points displacement time series of the monitored scenario (red squares enhance Point 8 accelerations).

gies for instability detection, mapping, monitoring, and forecasting (Confuorto et al., 2017). In order to provide information on the nature, extent, and activation frequency of an- cient landslides, standard detection, and mapping procedures need a combination of field-based studies and advanced techniques, such as remote sensing data analysis and geophysi- 

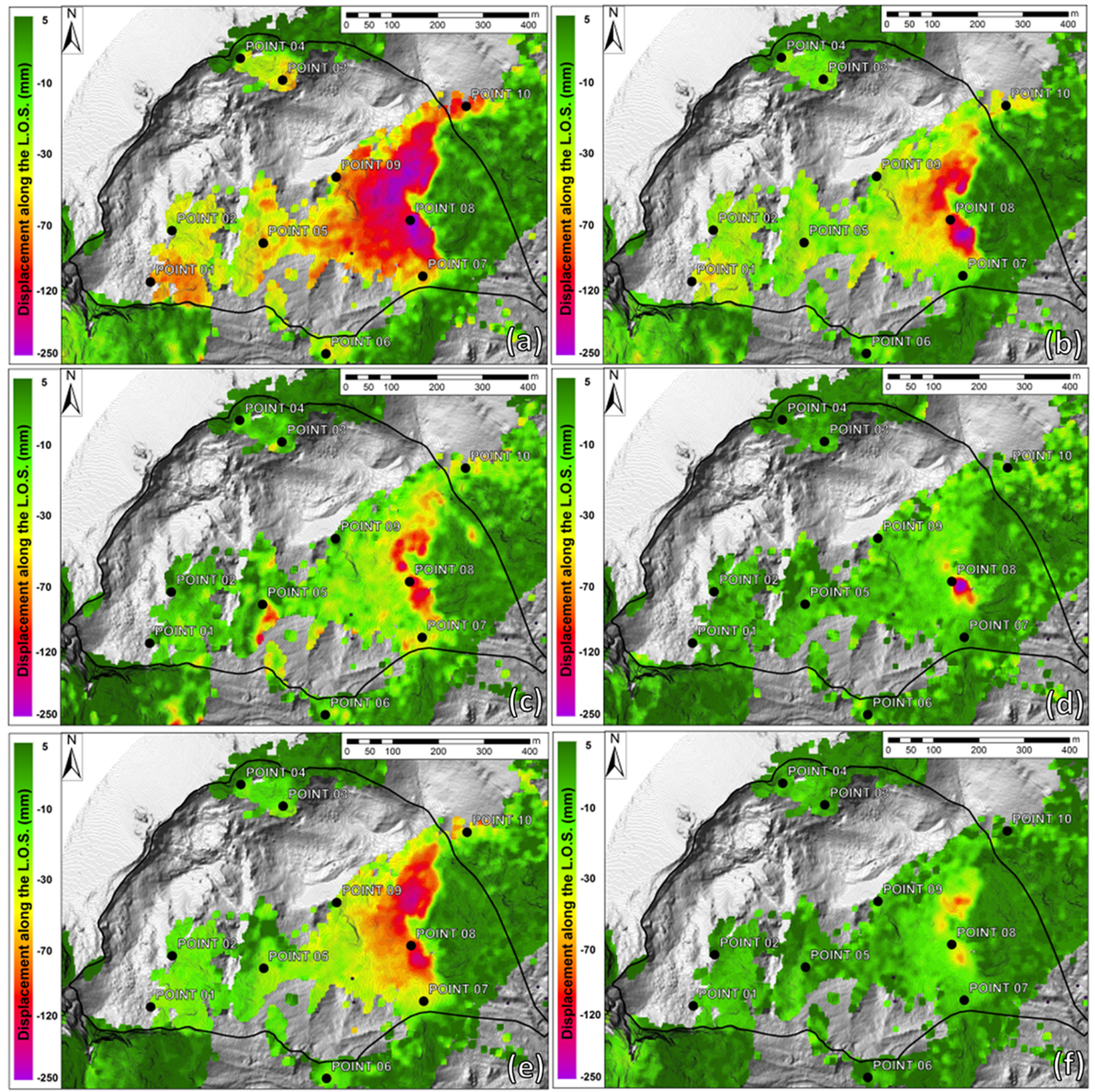

Figure 9. Selection of MCD maps from the GB-InSAR dataset: (a) December 2010 (232 mm cumulated peak displacement); (b) January 2011 (214 mm); (c) March 2011 (173 mm); (d) May 2011 (244 mm); (e) November 2011 (174 mm); (f) November 2012 (106 mm).

cal investigations (Ciampalini et al., 2015; Lotti et al., 2015; Del Soldato et al., 2016; Morelli et al., 2017; Pazzi et al., $2017 \mathrm{a}, \mathrm{b})$. In this context GB-InSAR represents a versatile and flexible technology, allowing for rapid changes in the type of data acquisition (geometry and temporal sampling) based on the characteristics of the monitored slope failure, which is capable of assessing the extent and the magnitude of the landslide residual hazard (Di Traglia et al., 2014a, b,
2015; Carlà et al., 2016). In the presented case study the 2 -year continuous GB-InSAR monitoring campaign made it possible to measure the slope displacement with millimetric accuracy over a $1.2 \mathrm{~km}$ square landslide area, enabling the analyses of the evolution pattern connected to the landslide residual hazard. The measured deformation pattern was almost always consistent, in terms of extent and values, with the results obtained in some specific benchmark by an auto- 

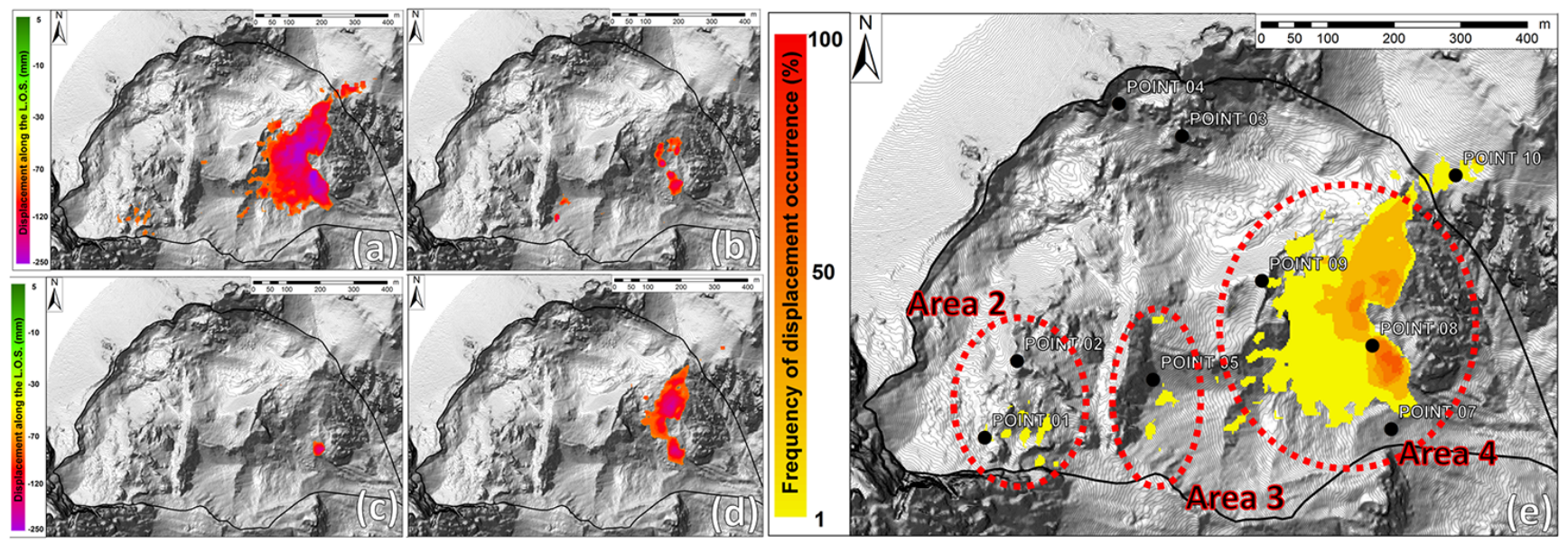

Figure 10. Residual reactivation maps obtained from selected MCD maps by means of the employed MATLAB code analysis: (a) December 2010; (b) March 2011; (c) May 2011; (d) November 2011; (e) frequency map of the reactivation of the critical residual displacement sectors, classified based on their activation frequency.

mated total station monitoring network (Frigerio et al., 2014; Bossi et al., 2015), working approximately in parallel with the GB-InSAR system.

By comparing the landslide geomorphological map (Frodella et al., 2014) with the ICD displacement map of the whole monitored period (Fig. 11), the four critical areas shown in Fig. 7 are analysed in detail:

- Area 1, including measuring points 3 and 4, is located in the northern side of detachment sector (Fig. 11a). In the first few months (between December 2010 and March 2011) the points recorded a peak of displacements of about $260 \mathrm{~mm}$ (Point 4) and $150 \mathrm{~mm}$ (Point 3 ); after this period the displacement decreased up to 8 November 2011. Between 8 and 12 November, during a major rainfall event $(68 \mathrm{~mm})$, the displacements increased again (Fig. 11b). The displacements recorded by the points within Area 1 may be related to deformations affecting the deposits placed along the steep scarp connected to the main crown delimiting the DSGSD (Fig. 4).

- Area 2 is located in the detachment sector (SW side of the DSGSD). Two measuring points (points 1 and 2) therein located (Fig. 11d) recorded a peak of displacement of about $170 \mathrm{~mm}$ (Point 1) and $130 \mathrm{~mm}$ (Point 2) respectively, between December 2010 and March 2011. The ground deformations recorded by these points are related to slope-waste deposition due to the gravity affecting the coarse material infilling this sector, such as ancient rock avalanche deposits (Point 1) and detensioned rock mass portions (Point 2) (Fig. 4).

- Area 3 represents the border between detachment and dismantling sectors and is located upstream of the 2010 event scarp (Fig. 11c). Its kinematics is represented by
Point 5 behaviour, showing a trend similar to P1, which may be associated with the sliding of the partly cemented and stabilized detrital cover material (Figs. 411d).

- Area 4 represents the lowermost portion of dismantling sector. Three measuring points are therein located: points 7, 8, and 9 (Fig. 11e and f). Points 7 and 8 display the kinematics the detrital cover surrounding the 2010 debris flow triggering area. Both control points show acceleration periods alternating with periods of stability. In particular, the trend of P8, located near the Rotolon Creek ephemeral springs and channels (Frodella et al., 2014, 2015), shows a correlation with cumulative precipitation above a threshold value of about $100 \mathrm{~mm}$ (Fig. 11f), which contributes to the subsurface water circulation within the detachment sector's loose detrital cover.

This suggests that the recorded displacements may be associated to the spring erosion within the detrital cover. This point records the maximum displacement of the entire area $(\mathrm{ICD} \approx 1236 \mathrm{~mm})$ monitored by GB-InSAR system. The area is apparently dominated by superficial processes, such as widespread soil erosion and slope-waste deposition due to gravity. Measuring Point 9, located near the dismantling sector upstream limit, records cumulative displacement of $445 \mathrm{~mm}$ and shows an irregular trend mainly due to its location near vegetated areas (Figs. 4-11f).

The use of GB-InSAR ICD maps and the integration with geomorphological field surveys proved its usefulness in recognizing Area 4 (located within the DSGSD dismantling sector; Figs. 3 and 7) as the most hazardous sector within the monitored scenario, due to the widespread and intense recorded cumulated displacements $(2437 \mathrm{~mm})$, its geomorphological features (steep slope, very coarse loose debris and 


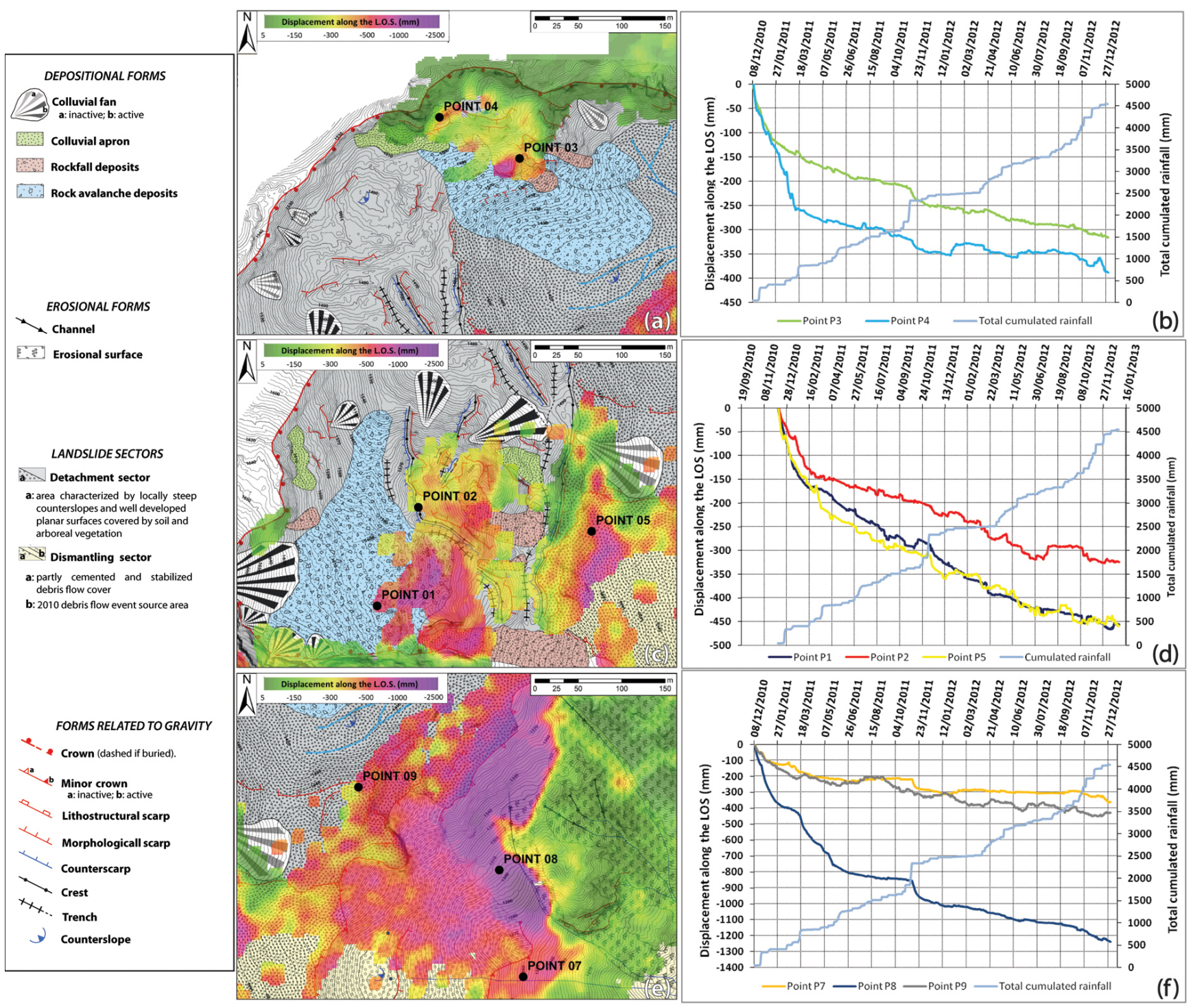

Figure 11. Integration between geomorphological map (modified after Frodella et al., 2014), the ICD maps displacement maps of whole monitored period, and the control points displacements time series: (a) the zoom of the Area 1 shown in Fig. 7d; (b) the displacements time series of P4 and P3; (c) zoom of the Area 2 and Area 3 shown in Fig. 7d; (d) the displacement time series of points 1, 2, and 5; (e) zoom of Area 4 shown in Fig. 7d; (f) the displacement time series of points 7, 8, and 9.

widespread surface erosional processes underway due to the presence of ephemeral springs), and frequency of reactivations (Fig. 10).

The main triggering factor for these shallow remobilizations ongoing in this area is intense rainfall events, as highlighted by measuring Point 8 time series (Fig. 8). Area 3 (recording $960 \mathrm{~mm}$ of total cumulated displacements) falls as well within the dismantling sector detrital cover, and was considered the second most hazardous landslide sector within the monitored scenario. Other areas characterized by relevant residual cumulated displacement were identified in Area $1(737 \mathrm{~mm})$ and Area $2(751 \mathrm{~mm})$, corresponding to the material infilling the detachment sector (Fig. 2), but they were not considered hazardous due to a $300 \mathrm{~m}$ long and $20 \mathrm{~m}$ high $\mathrm{N}-\mathrm{S}$ trending trench acting as a physical barrier separating the upper detachment sector from the lowermost dismantling sector. Furthermore, the comparison amongst the MCD maps (Figs. 9 and 10) highlighted widespread and frequent residual displacements taking place in Area 4 during the wet autumn-winter months (December $2010=232 \mathrm{~mm}$; January $2011=214 \mathrm{~mm}$; March $2011=173 \mathrm{~mm}$; November $2011,2012=174$ and $106 \mathrm{~mm}$ respectively). Nevertheless, in May 2011 Area 4 reached the highest MCD in the monitored period $(244 \mathrm{~mm})$, although concentrated in a limited sector located near measuring Point 8 (Fig. 9d). 
In this framework, based on the surface of the deformation areas and the increasing trends of displacement time series, four alert messages were obtained and communicated: (i) 19 March 2011 (pre-alarm condition), (ii) 7 April 2011 (alarm condition), (iii) 8-12 November 2011 (pre-alarm condition), and (iv) 10-12 November 2012 (pre-alarm condition, Fig. 6). All these events were located in the area monitored by measuring Point 8 , but under none of these circumstances did the debris develop in significant slope failures and runout, although rainfall comparable to that of November 2010 had hit the area every time. In any case, the GB-InSAR, benefiting from extensive coverage of the observations, registered in details a brief dislocation of surficial material and followed the gradual return to the stability conditions up to the most critical observed pixels that from time to time appeared irregularly dislocated around Point 8.

\section{Conclusions}

In the context of the 2010 hazardous events affecting the Rotolon Creek valley, a local-scale GB-InSAR system was implemented for (i) mapping and monitoring slope landslide residual deformations and (ii) early warning purposes in case of landslide reactivations. The objective was to assure the safety of both the valley's inhabitants and the personnel involved in the post-event recovery phase. The radar system acquired GB-InSAR data every $10 \mathrm{~min}$, from which cumulated 2-D displacement maps and displacements time series of 10 measuring points were obtained. The analysed GB-InSAR data were uploaded both on a dedicated web-based interface and remote ftp server, allowing for (i) a daily near-real-time and on-routine data visualization and (ii) on demand analysis in case of critical weather events. In this context, based on the surface of the deformation areas and the increasing trends of displacement time series, four monitoring alerts were obtained and a 16-month weekly monitoring bulletin campaign was performed (May 2011-September 2012). All of the monitoring data were shared with the technical stakeholders and decision makers involved in the emergency management.

Given the recorded residual deformations, four critical sectors were identified in the monitored scenario on the basis of the measured cumulated displacements, frequency of activation, and geomorphological features. Amongst these sectors, Area 3 and in particular Area 4 (recording respectively 960 and $2437 \mathrm{~mm}$ of total cumulated displacements) were considered the most hazardous for potential debris flow reactivations. The latter areas are in fact located within a steep landslide sector characterized by loose detrital cover, affected by soil erosion and slope-waste deposition (dismantling sector). The displacement time series of the GB-InSAR measuring points provided information on the landslide kinematics: displacements range from $337 \mathrm{~mm}$ (Point 6) to $1476 \mathrm{~mm}$ (Point 8). This latter point displays the monitored area's cumulated peak displacements, showing two acceleration periods (mid-March 2011 and beginning of November 2011) triggered by intense precipitations, alternating with a more linear trend. The kinematics of the other representative measuring points is related either to deformations affecting the deposits placed along the steep scarp connected to the main DSGSD (points 3-4) or to slope-waste deposition due to gravity affecting the coarse material infilling the detachment sector (points 1-2-5).

The comparison amongst the MCD maps highlighted a first phase of widespread residual displacements (December 2010). In the following period, ground deformation took place in limited sectors within Area 4, except for a widespread reactivation recorded in November 2011. The acquired radar data suggest a complex nature of the monitored landslide: its geomorphological features (e.g. rough topography, stepped profile in its upper sector, showing scarps, counterscarps, ridges, trenches and counter-slopes, toe bulging) document the activity of deep-seated longterm processes. The radar data also recorded the wide spectrum of short-term secondary instability phenomena, probably related to erosional-depositional gravitational processes (detachment sector) and soil erosion/slope-waste deposition (dismantling sector). Although this latter sector represents the most hazardous area within the landslide, the displacements acting therein during the analysed timespan appear to be related to ephemeral spring erosion located within the loose detrital cover. This suggests that these processes are only the surficial and secondary expression of a more complex deep-seated landslide system.

The monitoring system adopted provided all of the technical personnel and decision-making local authorities involved in the post-crisis management activities with a reliable, rapid, and easy communication system of the results of the monitoring campaign. This favoured an enhanced understanding of such a critical landslide scenario (a populated mountainous area particularly devoted to tourist activities) during the postemergency management activities. Furthermore, the methodology could be profitably adapted, modified, and updated in other geological contexts.

Data availability. The present paper concerns a methodology. The data used in this paper can be requested from the corresponding author.

Competing interests. The authors declare that they have no conflict of interest.

Special issue statement. This article is part of the special issue "Landslide early warning systems: monitoring systems, rainfall thresholds, warning models, performance evaluation and risk perception". It is not associated with a conference. 
Acknowledgements. The GB-InSAR apparatus used in this application was designed and produced by Ellegi s.r.l. and based on the proprietary LiSALab GB-InSAR technology, derived from the evolution and improvement of LiSA technology (licensed by the Ispra Joint Research Centre of the European Commission). We also would like to thank the Veneto Soil Defence Regional Direction for providing lidar and aerial photo data.

Edited by: Luca Piciullo

Reviewed by: two anonymous referees

\section{References}

Abellán, A., Vilaplana, J. M., and Martínez, J.: Application of a long-range terrestrial laser scanner to a detailed rockfall study at Vall de Núria (Eastern pyrenees, Spain), Eng. Geol., 88, 136148, 2006.

Antonello, G., Casagli, N., Farina, P., Leva, D., Nico, G., Sieber, A. J., and Tarchi, D.: Ground-based SAR interferometry for monitoring mass movements, Landslides, 1, 21-28, 2004.

Bamler, R. and Hartl, P.: Synthetic aperture radar interferometry, Inverse Probl., 14, 1-54, 1998.

Bardi, F., Frodella, W., Ciampalini, A., Bianchini, S., Del Ventisette, C., Gigli, G., Fanti, R., Moretti, S., Basile, G., and Casagli, N.: Integration between ground based and satellite SAR data in landslide mapping: the San Fratello case study, Geomorphology, 223, 45-60, 2014.

Bardi, F., Raspini, F., Frodella, W., Lombardi, L., Nocentini, M., Gigli, G., Morelli, S., Corsini, A., and Casagli, N.: Monitoring the rapid-moving reactivation of Earth flows by means of GB-InSAR: the April 2013 Capriglio Landslide (Northern Appennines, Italy), Remote Sensing, 9, 165, https://doi.org/10.3390/rs9020165, 2017a.

Bardi, F., Raspini, F., Frodella, W., Lombardi, L., Nocentini, M., Gigli, G., Morelli, S., Corsini, A., and Casagli, N.: Remote sensing mapping and monitoring of the Capriglio landslide (Parma Province, northern Italy), in: Advancing Culture of Living With Landslides, Vol. 3 - Advances in Landslide Technology, edited by: Mikos, M., Arbanas, Ž., Yin, Y., Sassa, K., Springer International Publishing, Switzerland, 231238, https://doi.org/10.1007/978-3-319-53487-9_26, 2017b.

Bertolaso, G., De Bernardinis, B., Bosi, V., Cardaci, C., Ciolli, S., Colozza, R., Cristiani, C., Mangione, D., Ricciardi, A., Rosi, M., Scalzo, A., and Soddu, P.: Civil protection preparedness and response to the 2007 eruptive crisis of Stromboli volcano, Italy, J. Volcanol. Geoth. Res., 182, 269-277, 2009.

Bossi, G., Crema, S., Frigerio, S., Mantovani, M., Marcato, G., Pasuto, A., Schenato, L., and Cavalli, M.: The Rotolon catchment early-warning system, in: Engineering Geology for Society and Territory, edited by: Lollino, G. et al., Springer International Publishing, Switzerland, vol. 3, 91-95, https://doi.org/10.1007/9783-319-09054-2_18, 2015.

Broussolle, J., Kyovtorov, V., Basso, M., Ferraro Di Silvi, E., Castiglione, G., Figueiredo Morgado, J., Giuliani, R., Oliveri, F., Sammartino, P. F., and Tarchi, D.: MELISSA, a new class of ground based InSAR system. An example of application in support to the Costa Concordia, ISPRS J. Photogramm., 91, 50-58, 2014.
Carlà, T., Intrieri, E., Di Traglia, F., and Casagli, N.: A statisticalbased approach for determining the intensity of unrest phases at Stromboli volcano (Southern Italy) using one-step-ahead forecasts of displacement time series, Nat. Hazards, 84, 669-683, 2016.

Casagli, N., Catani, F., Del Ventisette, C., and Luzi, G.: Monitoring, prediction, and early warning using ground-based radar interferometry, Landslides, 7, 291-301, 2010.

Casagli, N., Frodella, W., Morelli, S., Tofani, V., Ciampalini, A., Intrieri, E., Raspini, F., Rossi, G., Tanteri, L., and Lu, P.: Spaceborne, UAV and ground-based remote sensing techniques for landslide mapping, monitoring and early warning, Geoenvironmental Disasters, 4, https://doi.org/10.1186/s40677-017-0073-1, 2017a.

Casagli, N., Tofani, V., Morelli, S., Frodella, W., Ciampalini, A., Raspini, F., and Intrieri, E.: Remote sensing techniques in landslide mapping and monitoring, keynote lecture, in: Advancing Culture of Living With Landslides, Vol. 3 - Advances in Landslide Technology, edited by: Mikos, M., Arbanas, Ž., Yin, Y., Sassa, K., Springer International Publishing, Switzerland, 1-19, https://doi.org/10.1007/978-3-319-53487-9_1, 2017b.

Casu, F., Manzo, M., and Lanari, R.: A quantitative assessment of the SBAS algorithm performance for surface deformation retrieval from DInSAR data, Remote Sens. Environ., 102, 195210, 2006.

Chandler, J.: Effective application of automated digital photogrammetry for geomorphological research, Earth Surf. Proc. Land., 24, 51-63, 1999.

Ciampalini, A., Raspini, F., Bianchini, S., Frodella, W., Bardi, F., Lagomarsino, D., Di Traglia, F., Moretti, S., Proietti, C., Pagliara, P., Onori, R., Corazza, A., Duro, A., Basile, G., and Casagli, N.: Remote sensing as tool for development of landslide databases: the case of the Messina Province (Italy) geodatabase, Geomorphology, 249, 103-118, 2015.

Ciampalini, A., Raspini, F., Frodella, W., Bardi, F., Bianchini, S., and Moretti, S.: The effectiveness of high-resolution LiDAR data combined with PSInSAR data, Landslides, 13, 399-410, 2016.

Confuorto, P., Di Martire, D., Centolanza, G., Iglesias, R., Mallorqui, J. J., Novellino, A., Plank, S, Ramondini, M., Thuro, K., and Calcaterra, D.: Post-failure evolution analysis of a rainfalltriggered landslide by multi-temporal interferometry SAR approaches integrated with geotechnical analysis, Remote Sens. Environ., 188, 51-72, 2017.

Crosta, G. B.: Landslide, spreading, deep seated gravitational deformation: analysis, examples, problems and proposals, Geogr. Fis Din. Quat., 19, 297-313, 1996.

Crosta, G. B. and Agliardi, F.: Failure forecast for large rock slides by surface displacement measurements, Can. Geotech. J., 40, 176-191, 2003.

Cruden, D. M. and Varnes, D. J.: Landslides types and Processes, in: Landslides: Investigation and Mitigation, edited by: Turner, A. K., Schuster, R. L., Transportation Research Board Special Report 247, National Academy Press, Washington, DC, USA, 36-75, 1996.

Del Soldato, M., Segoni, S., De Vita, P., Pazzi, V., Tofani, V., and Moretti, S.: Thickness model of pyroclastic soils along mountain slopes of Campania (southern Italy), in: Landslides and Engineered Slopes. Experience, Theory and Practice, edited by: 
Aversa et al., Associazione Geotecnica Italaiana, Rome, Italy, ISBN:978-1-138-02988-0, 2016.

Del Ventisette, C., Intrieri, E., Luzi, G., Casagli, N., Fanti, R., and Leva, D.: Using ground based radar interferometry during emergency: the case of the A3 motorway (Calabria Region, Italy) threatened by a landslide, Nat. Hazards Earth Syst. Sci., 11, 2483-2495, https://doi.org/10.5194/nhess-11-2483-2011, 2011.

De Zanche, V. and Mietto, P.: Review of the Triassic sequence of Recoaro (Italy) and related problems, Rend. Soc. Geol. It. Padova, 4, 25-28, 1981.

Di Traglia, F., Intrieri, E., Nolesini, T., Bardi, F., Del Ventisette, C., Ferrigno, F., Frangioni, S., Frodella, W., Gigli, G., Lotti, A., Tacconi Stefanelli, C., Tanteri, L., Leva, D., and Casagli, N.: The ground-based InSAR monitoring system at Stromboli volcano: linking changes in displacement rate and intensity of persistent volcanic activity, B. Volcanol., 76, 786, https://doi.org/10.1007/s00445-013-0786-2, 2014a.

Di Traglia, F., Nolesini, T., Intrieri, E., Mugnai, F., Leva, D., Rosi, M., and Casagli, N.: Review of ten years of volcano deformations recorded by the ground-based InSAR monitoring system at Stromboli volcano: a tool to mitigate volcano flank dynamics and intense volcanic activity, Earth-Sci. Rev., 139, 317-335, 2014b.

Di Traglia, F., Battaglia, M., Nolesini, T., Lagomarsino, D., and Casagli, N.: Shifts in the eruptive styles at Stromboli in 20102014 revealed by ground-based InSAR data, Sci. Rep.-UK, 5, 13569, https://doi.org/10.1038/srep13569, 2015.

Fidolini, F., Pazzi, V., Frodella, W., Morelli, S., and Fanti, R.: Geomorphological characterization, monitoring and modeling of the Monte Rotolon complex landslide (Recoaro terme, Italy), Engineering Geology for Society and Territory, Springer International Publishing, Switzerland, vol. 2, 1311-1315, 2015.

Frigerio, S., Schenato, L., Bossi, G., Cavalli, M., Mantovani, M., Marcato, G., and Pasuto, A.: A web-based platform for automatic and continuous landslide monitoring: the Rotolon (Eastern Italian Alps) case study, Comput. Geosci., 63, 96-105, https://doi.org/10.1016/j.cageo.2013.10.015, 2014.

Frodella, W., Morelli, S., Fidolini, F., Pazzi, V., and Fanti, R.: Geomorphology of the Rotolon landslide (Veneto region, Italy), J. Maps, 10, 394-401, 2014.

Frodella, W., Fidolini, F., Morelli, S., and Pazzi, V.: Application of infrared thermography for landslide mapping: the Rotolon DSGDS case study, Rend. Online Soc. Geol. It., 35, 144-147, 2015.

Frodella, W., Ciampalini, A., Gigli, G., Lombardi, L., Raspini, F., Nocentini, M., Scardigli, C., and Casagli, N.: Synergic use of satellite and ground based remote sensing methods for monitoring the San Leo rock cliff (Northern Italy), Geomorphology, 264, 80-94, 2016.

Frodella, W., Morelli, S., and Pazzi, V.: Infrared thermographic surveys for landslide mapping and characterization: the Rotolon DSGSD (Norther Italy) case study, Ital. J. Eng. Geol. Environ., 1, 77-84, https://doi.org/10.4408/IJEGE.2017-01.S-07, 2017.

Kostinakis, K. G., Athanatopoulou, A. M., and Avramidis, I. E.: Orientation effects of horizontal seismic components on longitudinal reinforcement in R/C frame elements, Nat. Hazards Earth Syst. Sci., 12, 1-10, https://doi.org/10.5194/nhess-12-1-2012, 2012.

Gigli, G., Intrieri, E., Lombardi, L., Nocentini, M., Frodella, W., Balducci, M., Venanti, L. D., and Casagli, N.: Event scenario analysis for the design of rockslide countermeasures, J. Mt. Sci., 11, 1521-1530, 2014a.

Gigli, G., Frodella, W., Garfagnoli, F., Mugnai, F., Morelli, S., Menna, F., and Casagli, N.: 3-D geomechanical rock mass characterization for the evaluation of rockslide susceptibility scenarios, Landslides, 11, 131-140, 2014b.

Gigli, G., Morelli, S., Fornera, S., and Casagli, N.: Terrestrial laser scanner and geomechanical surveys for the rapid evaluation of rock fall susceptibility scenarios, Landslides, 11, 1-14, 2014c.

Gullà, G., Peduto, D., Borrelli, L., Antronico, L., and Fornaro, G.: Geometric and kinematic characterization of landslides affecting urban areas: the Lungro case study (Calabria, Southern Italy), Landslides, 14, 171-188, https://doi.org/10.1007/s10346015-0676-0, 2017.

Guzzetti, F., Mondini, A. C., Cardinali, M., Fiorucci, M., Santangelo, M., and Chang, K. T.: Landslide inventory maps: new tools for an old problem, Earth-Sci. Rev., 112, 1-25, 2012.

Intrieri, E., Gigli, G., Mugnai, F., Fanti, R., and Casagli, N.: Design and implementation of a landslide early warning system, Eng. Geol., 147, 124-136, 2012.

Intrieri, E., Gigli, G., Casagli, N., and Nadim, F.: Brief communication "Landslide Early Warning System: toolbox and general concepts", Nat. Hazards Earth Syst. Sci., 13, 85-90, https://doi.org/10.5194/nhess-13-85-2013, 2013.

Jaboyedoff, M., Oppikofer, T., Abellán, A., Derron, M. H., Loye, A., Metzger, R., and Pedrazzini, A.: Use of LIDAR in landslide investigations: a review, Nat. Hazards, 61, 5-28, 2012.

Lombardi, L., Nocentini, M., Frodella, W., Nolesini, T., Bardi, F., Intrieri, E., Carlà, T., Solari, L., Dotta, G., Ferrigno, F., and Casagli, N.: The Calatabiano landslide (southern Italy): preliminary GB-InSAR monitoring data and remote 3D mapping, Landslides, 14, 685-696, https://doi.org/10.1007/s10346-016-0767-6, 2017.

Lotti, A., Saccorotti, G., Fiaschi, A., Matassoni, L., Gigli, G., Pazzi, V., and Casagli, N.: Seismic monitoring of rockslide: the Torgiovannetto quarry (Central Apennines, Italy), in: Engineering Geology for Society and Territory - Vol. 2, edited by: Lollino, G. et al., Springer International Publishing, Switzerland, 1537-1540, https://doi.org/10.1007/978-3319-09057-3_272, 2015.

Luzi, G., Pieraccini, M., Mecatti, D., Noferini, L., Guidi, G., Moia, F., and Atzeni, C.: Ground-based radar interferometry for landslides monitoring: atmospheric and instrumental decorrelation sources on experimental data, IEEE T. Geosci. Remote, 42, 2454-2466, 2004.

Luzi, G.: Ground Based SAR Interferometry: a novel tool for geosciences, in: Geoscience and Remote Sensing. New Achievements, edited by: Imperatore, P., Riccio, D., InTech, 1-26, https://doi.org/10.5772/9090, 2010.

Monserrat, O., Crosetto, M., and Luzi, G.: A review of groundbased SAR interferometry for deformation measurement, ISPRS J. Photogramm., 93, 40-48, 2014.

Morelli, S., Pazzi, V., Monroy, V. H. G., and Casagli, N.: Residual slope stability in low order streams of angangueo mining area (Michoacán, Mexico) after the 2010 Debris flows, in: Advancing Culture of Living With Landslides, Vol. 4 - Diversity of Landslide Forms, edited by: Mikos, M., Casagli, N., Yin, Y., Sassa, K., Springer International Publishing, Switzerland, 651660, https://doi.org/10.1007/978-3-319-53485-5_75, 2017. 
Nicodemo G, Peduto D, Ferlisi S and Maccabiani, J.: Investigating building settlements via very high resolution SAR sensors, in: Life-Cycle of Engineering Systems: Emphasis on Sustainable Civil Infrastructure, edited by: Bakker, J., Frangopol, D. M., van Breugel, K., 2017, Taylor and Francis Group, London, 22562263, 2016.

Nolesini, T., Di Traglia, F., Del Ventisette, C., Moretti, S., and Casagli, N.: Deformations and slope instability on Stromboli volcano: integration of GBInSAR data and analog modeling, Geomorphology, 180, 242-254, 2013.

Nolesini, T., Frodella, W., Bianchini, S., and Casagli, N.: Detecting slope and urban potential unstable areas by means of multi-platform remote sensing techniques: the Volterra (Italy) case study, Remote Sensing, 8, 746, https://doi.org/10.3390/rs8090746, 2016.

Pagliara, P., Basile, G., Cara, P., Corazza, A., Duro, A., Manfrè, B., Onori, R., Proietti, C., and Sansone, V.: Integration of earth observation and ground-based HR data in the civil protection emergency cycle: the case of the DORIS project, in: Mathematics of Planet Earth, Lecture Notes in Earth System Sciences, edited by: Pardo-Igúzquiza, E., Guardiola-Albert, C., Heredia, J., MorenoMerino, L., Durán, J. J., Vargas-Guzmán, J. A., Springer, Berlin Heidelberg, 263-266, 2014.

Pazzi, V., Tanteri, L., Bicocchi, G., Caselli, A., D’ Ambosio, M., and Fanti, R.: H/V technique for the rapid detection of landslide slip surface(s): assessment of the optimized measurements spatial distribution, in: Advancing Culture of Living With Landslides, Vol. 2 - Advances in Landslide Science, edited by: Mikos, M., Tiwari, B., Yin, Y., Sassa, K., Springer International Publishing, Switzerland, 335-343, https://doi.org/10.1007/978-3-31953498-5_38, 2017a.

Pazzi, V., Tanteri, L., Bicocchi, G., D’Ambrosio, M., Caselli, A., and Fanti, R.: H/V measurements as an effective tool for the reliable detection of landslide slip surfaces: case studies of Castagnola (La Spezia, Italy) and Roccalbegna (Grosseto, Italy), Phys. Chem. Earth, 98, 136-153, https://doi.org/10.1016/j.pce.2016.10.014, 2017b.

Peduto, D., Ferlisi, S., Nicodemo, G., Reale, D., Pisciotta, G., and Gullà G.: Empirical fragility and vulnerability curves for buildings exposed to slow-moving landslides at medium and large scales, Landslides, in press, https://doi.org/10.1007/s10346-0170826-7, 2017a.

Peduto, D., Nicodemo, G., Maccabiani, J., and Ferlisi, S.: Multi-scale analysis of settlement induced building damage using damage surveys and DInSAR data: a case study in the Netherlands. Eng. Geol., 218, 117-133, https://doi.org/10.1016/j.enggeo.2016.12.018, 2017 b.
Pieraccini, M., Tarchi, D., Rudolf, H., Leva, D., Luzi, G., Bartoli, G., and Atzeni, C.: Structural static testing by interferometric synthetic radar, NDT\&E Int., 33, 565-570, 2000.

Pieraccini, M., Casagli, N., Luzi, G., Tarchi, D., Mecatti, D., Noferini, L., and Atzeni, C.: Landslide monitoring by groundbased radar interferometry: a field test in Valdarno (Italy), Int. J. Remote Sens., 24, 1385-1391, 2002.

Salvatici, T., Morelli, S., Pazzi, V., Frodella, W., and Fanti, R.: Debris flow hazard assessment by means of numerical simulations: implications for the Rotolon Creek Valley (Northern Italy), J. Mt. Sci, 14, 636-648, https://doi.org/10.1007/s11629-016-41977, 2017.

Tarchi, D., Ohlmer, E., and Sieber, A. J.: Monitoring of structural changes by radar interferometry, Res. Nondestruct. Eval., 9, 213 225, 1997.

Tarchi, D., Casagli, N., Fanti, R., Leva, D., Luzi, G., Pasuto, A., Pieraccini, M., and Silvano, S.: Landslide monitoring by using ground-based SAR interferometry: an example of application to the Tessina landslide in Italy, Eng. Geol., 68, 15-30, 2003.

Tapete, D., Gigli, G., Mugnai, F., Vannocci, P., Pecchioni, E., Morelli, S., Fanti, R., and Casagli, N.: Correlation between erosion patterns and rockfall hazard susceptibility in hilltop fortifications by terrestrial laser scanning and diagnostic investigations, in: IEEE International Geoscience and Remote Sensing Symposium. Remote Sensing for a Dynamic Earth, Munich, Germany, 22-27 July 2012, Germany, 4809-4812, ISBN 978-14673-1159-5, 2012.

Tofani, V., Raspini, F., Catani, F., and Casagli, N.: Persistent scatterer interferometry (PSI) technique for landslide characterization and monitoring, in: Landslide Science for a Safer Geoenvironment Methods of Landslide Studies 2, edited by: Sassa, K., Canuti, P., Yueping, Y., Springer International Publishing, Switzerland, 351-357, ISBN: 9783319050492, 2014.

Zhang, Z., Zheng, S., and Zhan, Z.: Digital terrestrial photogrammetry with photo total station, International Archives of Photogrammetry and Remote Sensing, Istanbul, Turkey, 232-236, 2004.

Zischinsky, U.: Uber sackungen, Rock Mech., 1, 30-52, 1969. 